\title{
Epiploic Appendagitis: A Riddle for Right Lower Quadrant Pain!
}

\author{
Lovenish Bains $^{a} \quad$ Akshay Bahadur $^{a}$ Pawan Lal ${ }^{b} \quad$ Rahul Bhatia $^{b}$ \\ Nirmala Singh $^{c}$ Daljit Kaur ${ }^{d}$ \\ aDepartment of Surgery, Maulana Azad Medical College, New Delhi, India; ${ }^{\text {b}}$ Department of \\ Surgery, Dr. Hedgewar Arogya Sansthan, Delhi, India; 'CMO Incharge (SAG), VVWC-CGHS, \\ Delhi, India; dDepartment of Transfusion Medicine, All India Institute of Medical Sciences, \\ Rishikesh, India
}

\section{Keywords}

Appendicitis · Computed tomography · Epiploic appendagitis · Right lower quadrant pain

\begin{abstract}
Epiploic appendagitis (EA) is inflammation of epiploic appendages, which are pedunculated fatty structures, extend from the cecum to the rectosigmoid junction, and are covered by the peritoneum. Torsion, infarction, and inflammation of it present with acute lower abdominal pain and localized tenderness in a well-looking patient. It poses as diagnostic conundrum due to its rarity and not picked by conventional radiography. A 50-year-old male presented with pain in RLQ for past 1 day, which kept on increasing without any other symptoms. His abdomen was soft with tenderness localized to the right lower quadrant (RLQ), classically at McBurney's point along with mild peritonism. Rest laboratory test, chest, and abdominal X-ray were normal except slight leukocytosis. Ultrasound was inconclusive. A working clinical diagnosis of appendicitis was made. Patient did not consent for surgery and was started on antibiotics with pain killers. With no significant improvement, he underwent CT scan which revealed focal area of soft-tissue attenuation along the lateral wall of ascending colon with fat stranding. He was diagnosed as EA and improved on conservative treatment. EA of RLQ of abdomen mimics acute appendicitis and can be considered as an uncommon differential diagnosis in presence of radiological findings of normal-appearing appendix. CT is the investigation of choice, and treatment is essentially conservative. Further, if appendix is found normal at exploration, surrounding epiploic appendages of the cecum and ascending colon should also be evaluated carefully for inflammation/hematoma/gangrene, besides looking for Meckel's diverticulum.
\end{abstract}




\section{Introduction}

Epiploic appendagitis (EA) is an inflammation of epiploic appendages, which are 1-2 cm thick, $0.5-5 \mathrm{~cm}$ long, 50-100 in number, pedunculated fatty structures arranged in 2 separate longitudinal rows protruding through colon $[1,2]$. Covered by peritoneum, epiploic appendages extend from the cecum to the rectosigmoid junction [3]. Maximum numbers of epiploic appendages are in the cecum and sigmoid colon but rarely in the rectum [3].

EA mimics common abdominal emergencies depending on the site of involvement, thereby causing a diagnostic dilemma. EA typically presents with acute lower abdominal pain and localized tenderness in a well-looking patient. As the clinical presentation is nonspecific, EA is usually confused with other conditions such as acute appendicitis and acute diverticulitis [4].

As being not kept in the differential diagnosis, epiploic appendagitis can result in unnecessary hospitalization and medications, dietary restrictions, financial burden, and sometimes unnecessary surgery to the patient. Here, we describe a case of a 50-year-old male patient, who presented with right lower quadrant (RLQ) pain secondary to epiploic appendagitis of the ascending colon, which mimicked classical appendicitis by history and clinical examination until refuted by CT findings of EA.

\section{Case Summary}

A 50-year-old male (BMI 26) presented with pain in RLQ for past 1 day. Initially, the pain was mild, but it kept on increasing till he consulted us. The pain was sharp with pain score at presentation 7 out of 10 on visual analog scale. Patient also gave history of discomfort in abdomen while passing stool for past 2 days. There was no nausea, vomiting, fever, change in bowel habits, or any urinary complaint. There was no past history of chronic disease or surgical intervention.

On examination, the patient was afebrile and hemodynamically stable. His temperature was $36.2^{\circ} \mathrm{C}$, heart rate 70 beats $/ \mathrm{min}$, blood pressure $120 / 86 \mathrm{~mm} \mathrm{Hg}$, respiratory rate 16 breaths $/ \mathrm{min}$, and $\mathrm{SPO}_{2} 98 \%$ at room air. His abdomen was nondistended, soft with tenderness localized to the RLQ, classically at McBurney's point along with mild peritonism. Rest physical examination was otherwise unremarkable. Chest and abdominal X-ray were essentially normal. Laboratory results showed a white cell count of $11,500 /$ cubic $\mathrm{mm}$ with $76 \%$ neutrophils, hemoglobin $14.2 \mathrm{gm} / \mathrm{dL}$, C-reactive protein $24 \mathrm{mg} / \mathrm{L}$ with normal liver function tests and kidney function tests. Urine analysis was unremarkable for leukocytes and nitrite. His COVID-19 status was negative by RAT and later RT-PCR.

Abdominal ultrasound (USG) was normal study with no signs specific for appendicitis, apart from peritonism in the area. Patient was counseled about clinical diagnosis of appendicitis and need for surgery; however, patient did not consent for surgery. He was started on antibiotics (Inj. Ceftriaxone and Inj. Metronidazole) with pain killers. There was no significant change in his symptoms and signs at $36 \mathrm{~h}$, so he underwent computed tomography (CT) scan.

The CT-scan abdomen revealed focal area of soft-tissue attenuation measuring $11 \times 10$ $\mathrm{mm}$ in size with adjacent fat stranding closely abutting the lateral wall of ascending colon, as shown in Figures 1 and 2. Appendix appeared noninflamed in its entire length with wall-towall diameter of $5.3 \mathrm{~mm}$, as shown in Figure 3. Rest of the bowel loops appears normal. The findings were rechecked by senior radiologist, and a diagnosis of EA was suggested. His antibiotic therapy was stopped, and he was advised simple analgesic drugs and rest. Patient improved from day 3 and was completely relieved of symptoms at day 5 . Patient is doing fine up to 2 months of follow-up.

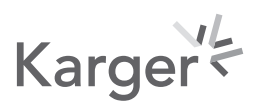



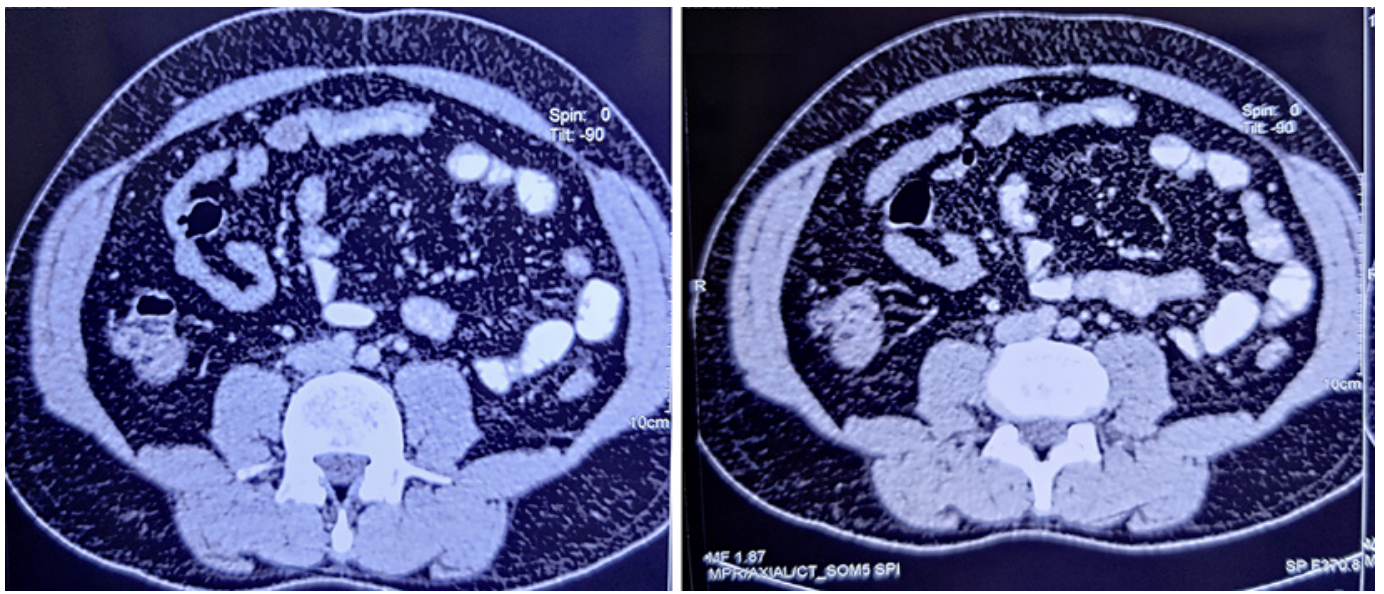

Fig. 1. CT-scan abdomen showed swelling with inflammatory changes along the lateral wall of ascending colon.

Fig. 2. Soft-tissue attenuation abutting the lateral wall of ascending colon (white arrow) suggesting appendagitis.
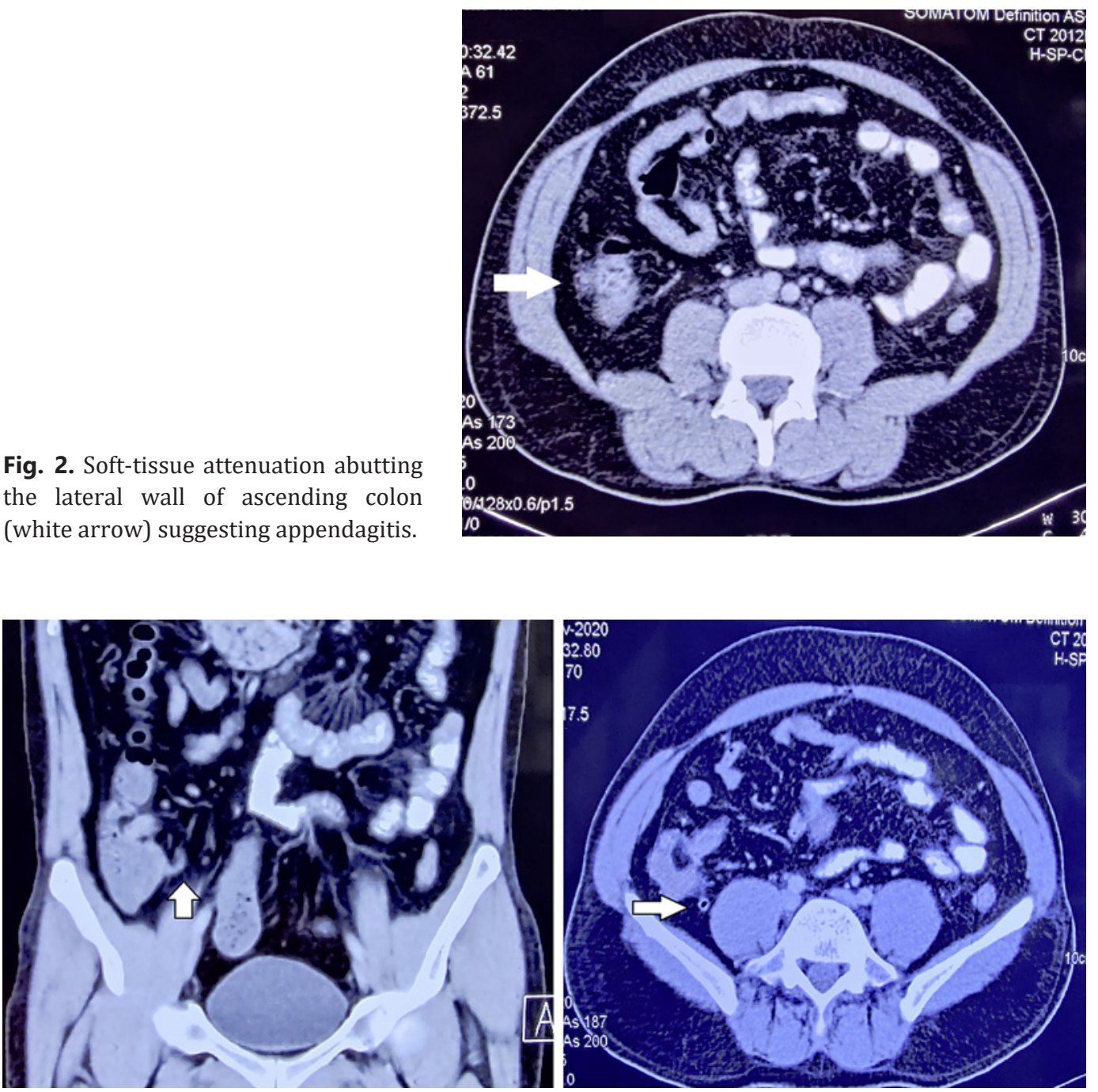

Fig. 3. Normal-appearing appendix in coronal and transverse plane (white arrows). 


\section{Discussion}

The description of the epiploic appendages in humans was first performed by Vesalius in 1543 [5]. However, Dockerty et al. [6] introduced the term EA and described an uncommon diagnosis, which is associated with acute, localized, left or right, lower quadrant pain.

Epiploic appendages are 50-100 pedunculated fatty structures located longitudinally on external surface of colon, close to anterior and posterior tenia coli [2]. Epiploic appendages, also known as epiploic appendices, are between 1-2 $\mathrm{cm}$ thick and $0.5-5 \mathrm{~cm}$ long $[1,2]$. The slender artery or less often two arteries are end arteries branching from the vasa recta longa of the colon and is drained by a tortuous vein passing through its narrow pedicle $[1,2]$. Excessive mobility along with pedunculated shape of epiploic appendages and limited blood supply makes it prone to torsion and ischemic infarction [3]. EA due to torsion and infarction was most commonly seen in the sigmoid colon (41.5\%) and the cecum $(15.1 \%)$ since these segments usually shelter the most prominent and elongated appendice epiploicae [7]. Besides torsion, spontaneous venous thrombosis of an appendageal draining vein is another cause of EA [4]. EA could also be secondary to inflamed organ in proximity such as colon (diverticulitis), appendix (appendicitis), gallbladder (cholecystitis), or pancreatitis [8].

EA typically presents with acute lower abdominal pain and localized tenderness in a welllooking patient. Male and female ratio is almost equal. Mild fever or leukocytosis may be present in some patients [7]. So far, more than 200 cases of EA have been published in indexed journals [7].

A clinical profile of 21 patients of EA searched in the indexed journals shows that almost 90\% have lower abdominal pain, as shown in Table 1 [9-26]. Fever and vomiting were absent in most patients, while tenderness of localized area was present in all patients. Rebound tenderness was present in 10 and guarding in 4 out of 21 cases including our case. Similarly, leukocytosis was present in 9 patients.

Diagnosis of EA is challenging due to absence of specific clinical features since it mimics with other diseases such as acute appendicitis, acute diverticulitis, segmental omental infarction, ruptured ovarian cyst. Diagnosis of EA should, therefore, be considered as a potential diagnosis by exclusion.

Obese patients, unusual exercise, presence of hernia are predisposing factor for inflammation of the epiploic appendages. EA is self-limited in most of the patients. Rarely, EA may complicate to adhesion, intestinal obstruction, intussusception, abscess formation, or peritonitis [27].

With increased use of CT scan in the evaluation of acute abdominal pain in recent years, most cases of EA are diagnosed using CT (preferred) and occasionally by USG [28]. Abdominal CT is an excellent imaging modality for identifying EA and should be considered the examination of choice, especially in young male patients with acute abdominal symptoms mimicking acute appendicitis or diverticulitis [28].

In our literature analysis as shown in Table 1, CT was preferred investigation of choice for diagnosis of EA, as it was inconclusive in only one out of 19 patient it was performed, while USG was either not performed (13 cases) or was inconclusive in 6 out of 7 cases it was performed.

The characteristic feature of EA in CT is a less than $50 \mathrm{~mm}$ oval lesion (range 15-35 mm) that has attenuation equivalent to that of fat that abuts the colonic wall surrounded by inflammatory changes [29]. Thickening of surrounding parietal peritoneum from the spread of inflammation may also be observed with or without thickening of colonic wall [29].

Treatment of the self-limiting EA is mostly conservative with anti-inflammatory medications and analgesia, which resolves within 1-2 weeks without the need for antibiotics and surgery [4]. Patient with recurrent EA and those who fails to resolve with conservative

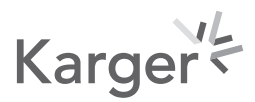




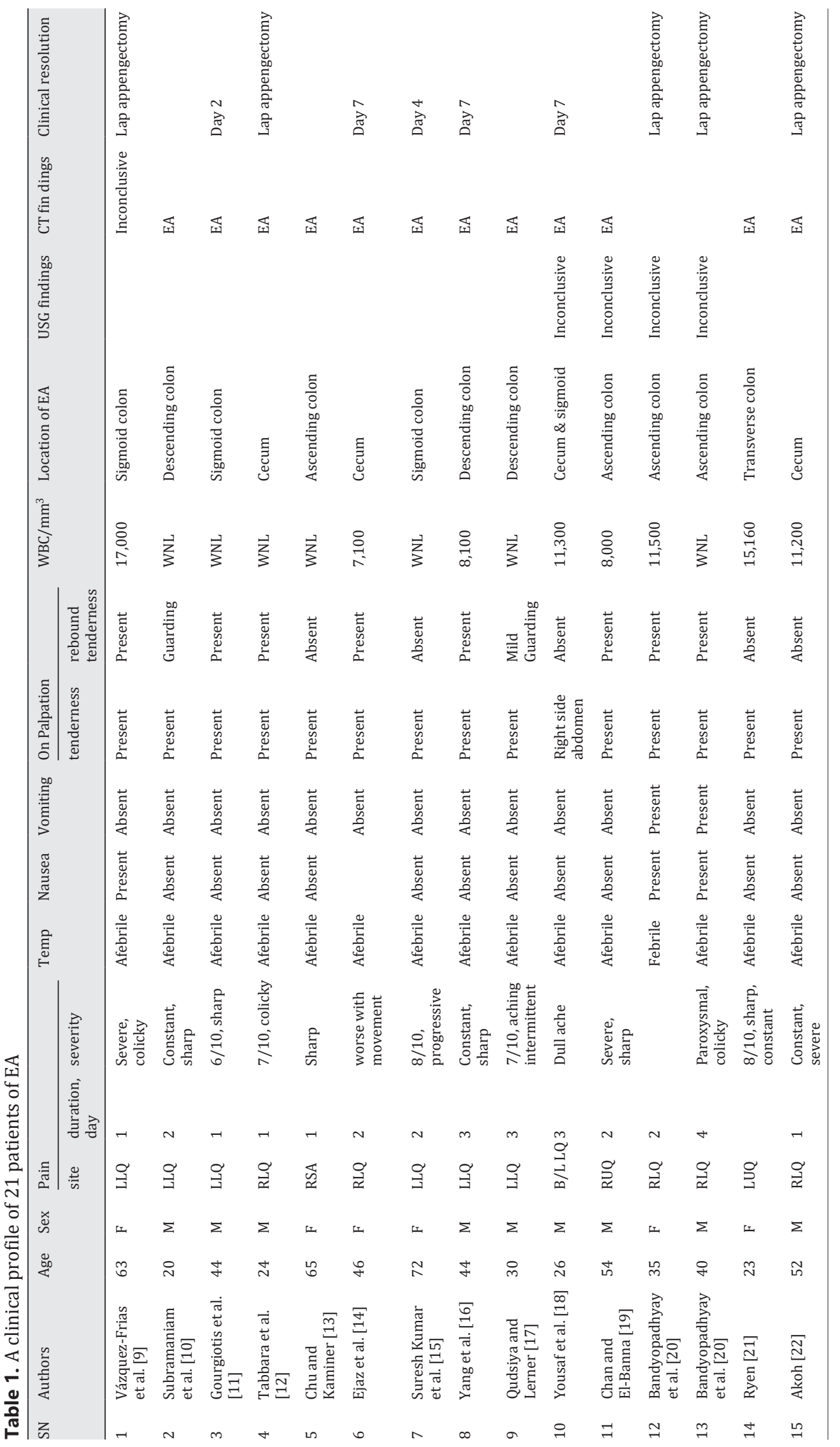




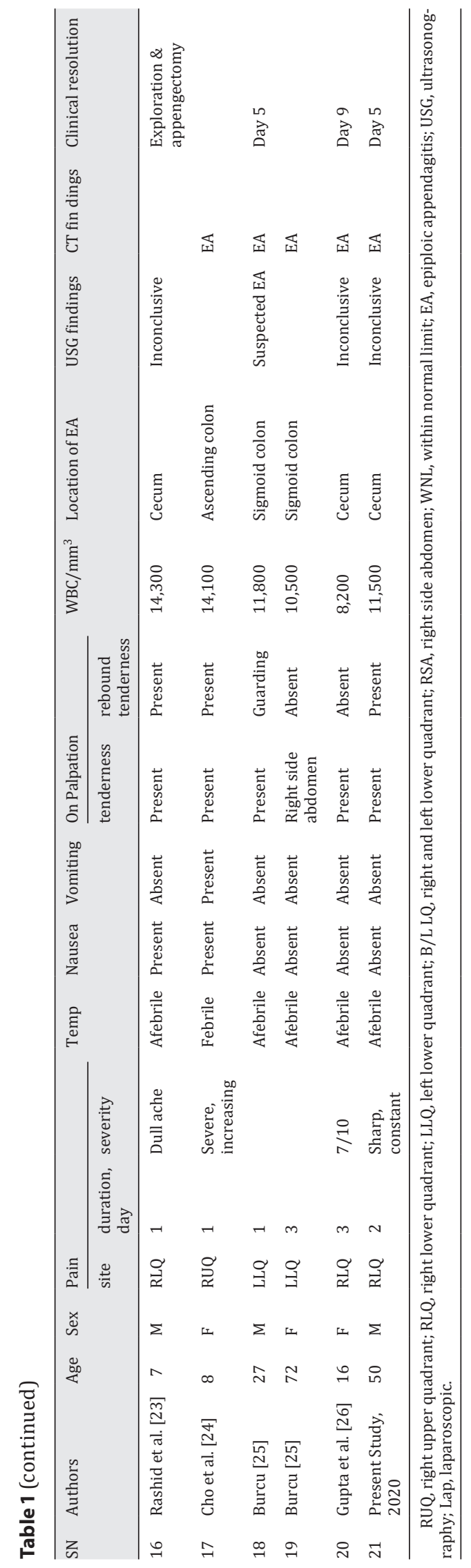

Karger' 
treatment, surgical ligation, and excision of the inflamed/necrosed appendage may be required $[2,4]$. Many patients of EA of RLQ of abdomen, who mimic appendicitis classically, undergo the knife. The appendix may be normal appearing; however, appendectomy is done to prevent future misdiagnosis. The patient of EA resolves with the pain killers given in the post-op period.

EA of RLQ of abdomen mimics acute appendicitis and can be considered as an uncommon differential diagnosis in presence of normal blood investigations and radiological findings of normal-appearing appendix. CT is the investigation of choice, and treatment is essentially conservative. Further, if appendix is found normal at exploration (open/laparoscopically), surrounding epiploic appendages of the cecum and ascending colon should also be evaluated carefully for inflammation/hematoma/gangrene, besides looking for Meckel's diverticulum. A greater awareness of this condition may lead to more cases being diagnosed as EA.

\section{Acknowledgement}

This manuscript does not include any nonauthor contributors to acknowledge.

\section{Statement of Ethics}

Approval for case report by the Institutional Ethics Committee is not required. Patient has given written informed consent for publication of this case report and the images.

\section{Conflict of Interest Statement}

The authors declare that they have no conflicting interests.

\section{Funding Sources}

No source of funding.

\section{Author Contributions}

L.B., A.B., and P.L. conceptualized the manuscript, reviewed the literature, analyzed data, and made major contribution to the writing of the manuscript. L.B. and P.L. performed the clinical examination, surgical treatment, and clinical follow-up. L.B., A.B., P.L., N.S., and D.K. performed final review and editing of the manuscript. All the authors have read and approved the final version of the manuscript.

\section{References}

1 Ross JA. Vascular loops in the appendices epiploicæ. Their anatomy and surgical significance, with a review of the surgical pathology of appendices epiploicæ. BJS. 1950;37(148):464-6.

2 Sand M, Gelos M, Bechara FG, Sand D, Wiese TH, Steinstraesser L, et al. Epiploic appendagitis: clinical characteristics of an uncommon surgical diagnosis. BMC Surg. 2007;7:11-7.

3 Singh AK, Gervais DA, Hahn PF, Sagar P, Mueller PR, Novelline RA. Acute epiploic appendagitis and its mimics. Radiographics. 2005;25(6):1521-34. 
4 Legome EL, Belton AL, Murray RE, Rao PM, Novelline RA. Epiploic appendagitis: the emergency department presentation1. J Emerg Med. 2002 Jan;22(1):9-13.

5 Vesalius A. De humani corporis fabrica libri septem (on the fabric of the human body). Ex officina Joannis Oporini; 1543

6 Dockerty MB, Lynn TE, Waugh JM. A clinicopathologic study of the epiploic appendages. Surg Gynecol Obstet. 1956 Oct;103(4):423-33.

7 Ghahremani GG, White EM, Hoff FL, Gore RM, Miller JW, Christ ML. Appendices epiploicae of the colon: radiologic and pathologic features. Radiographics. 1992;12(1):59-77.

8 Almeida AT, Melão L, Viamonte B, Cunha R, Pereira JM. Epiploic appendagitis: an entity frequently unknown to clinicians: diagnostic imaging, pitfalls, and look-alikes. Am J Roentgenol. 2009;193(5):1243-51.

9 Vázquez-Frias JA, Castañeda P, Valencia S, Cueto J. Laparoscopic diagnosis and treatment of an acute epiploic appendagitis with torsion and necrosis causing an acute abdomen. JSLS. 2000;4(3):247-50.

10 Subramaniam R. Acute appendagitis: emergency presentation and computed tomographic appearances. Emerg Med J. 2006;23(10):e53-3.

11 Gourgiotis S, Oikonomou C, Veloudis G, Lardou I, Pittaras G, Villias C. The diagnostic dilemma of primary epiploic appendagitis and how to establish a diagnosis. Oman Med J. 2016;31(3):235-7.

12 Tabbara TA, Alassaf OY, Kaouas MC. Acute epiploic appendigitis: diagnostic and laparoscopic approach. Int ] Surg Case Rep. 2018;44:157-60.

13 Chu EA, Kaminer E. Epiploic appendagitis: a rare cause of acute abdomen. Radiol Case Rep. 2018;13(3):599601.

14 Ejaz T, Saad E, Nabil A, Slattery J. Caecal epiploic appendagitis masquerading clinically as an acute appendicitis: a case report and brief literature review. Case Rep Surg. 2019;2019:6508642-3.

15 Suresh Kumar VC, Mani KK, Alwakkaa H, Shina J. Epiploic appendagitis: an often misdiagnosed cause of acute abdomen. Case Rep Gastroenterol. 2019;13(3):364-8.

16 Yang L, Jia M, Han P. Primary epiploic appendagitis as an unusual cause of acute abdominal pain in a middleaged male: a case report. Medicine. 2019;98(33):e16846-5.

17 Qudsiya Z, Lerner D. Acute epiploic appendagitis: an overlooked cause of acute abdominal pain. Cureus. 2020; 12(9):e10715-4.

18 Yousaf A, Ahmad S, Ghaffar F, Sajid S, Ikram S. Bilateral epiploic appendagitis: a rather benign but diagnostically challenging cause of acute abdominal pain. Cureus. 2020;12(4):e7897-9.

19 Chan E, El-Banna A. A case report of epiploic appendagitis as a mimic of acute cholecystitis. Int J Surg Case Rep. 2018;53:327-9.

20 Bandyopadhyay SK, Jain M, Khanna S, Sen B, Tantia O. Torsion of the epiploic appendix: an unusual cause of acute abdomen. J Minim Access Surg. 2007;3(2):70-2.

21 Ryen C. Epiploic appendagitis in a female patient with situs ambiguous abnormality. J Radiol Case Rep. 2009; 3(8):30-4

22 Akoh JA. Transplant nephrectomy. World J Transplant. 2011;1(1):4-12.

23 Rashid A, Nazir S, Hakim SY, Chalkoo MA. Epiploic appendagitis of caecum: a diagnostic dilemma. Ger Med Sci. 2012;10:Doc14-3.

24 Cho MS, Hwang-Bo S, Choi UY, Kim HS, Hahn SH. A case of epiploic appendagitis with acute gastroenteritis. Pediatr Gastroenterol Hepatol Nutr. 2014;17(4):263-5.

25 Burcu B. An unusual cause of acute abdomen - epiploic appendagitis: report of two cases. North Clin Istanbul. 2015;2(2):171-4.

26 Gupta N, Abdelmaseeh TA, Standish-Parkin L, Sitnitskaya Y. Clinical medical reviews and case reports case report: open access primary. Epiploic Appendagitis. 2016;3(6):10-1.

27 Carmichael DH, Organ CH. Epiploic disorders. Conditions of the epiploic appendages. Arch Surg. 1985 Oct; 120(10):1167-72.

28 Hasbahceci M, Erol C, Seker M. Epiploic appendagitis: is there need for surgery to confirm diagnosis in spite of clinical and radiological findings? World J Surg. 2012;36(2):441-6.

29 Singh AK, Gervais DA, Hahn PF, Rhea J, Mueller PR. CT appearance of acute appendagitis. AJR Am J Roentgenol. 2004;183(5):1303-7. 